\title{
Pulmonary function changes after thoracoscopic lobectomy versus intentional thoracoscopic segmentectomy for early-stage non-small cell lung cancer
}

\author{
Liang Chen ${ }^{1 \#}$, Zhitao Gu ${ }^{1 \#}$, Boyu Lin ${ }^{1}$, Weimin Wang ${ }^{2}$, Ning Xu ${ }^{1}$, Yuan Liu ${ }^{3}$, Chunyu Ji ${ }^{1}$, Wentao Fang ${ }^{1}$ \\ ${ }^{1}$ Department of Thoracic Surgery, Shanghai Chest Hospital, Shanghai Jiao Tong University, Shanghai, China; ${ }^{2}$ Department of Pulmonary Function, \\ Shanghai Chest Hospital, Shanghai Jiao Tong University, Shanghai, China; ${ }^{3}$ Statistics Center, Shanghai Chest Hospital, Shanghai Jiao Tong \\ University, Shanghai, China \\ Contributions: (I) Conception and design: L Chen, Z Gu, W Fang; (II) Administrative support: W Fang; (III) Provision of study materials or patients: \\ Z Gu, W Wang, C Ji, W Fang; (IV) Collection and assembly of data: L Chen, Z Gu, B Lin, W Wang, N Xu, W Fang; (V) Data analysis and \\ interpretation: L Chen, Z Gu, W Fang; (VI) Manuscript writing: All authors; (VII) Final approval of manuscript: All authors. \\ \#These authors contributed equally to this work. \\ Correspondence to: Wentao Fang, MD. Department of Thoracic Surgery, Shanghai Chest Hospital, Shanghai Jiao Tong University, 241 Huaihai Road \\ West, Shanghai 200030, China. Email: vwtfang@hotmail.com.
}

Background: Thoracoscopic segmentectomy is increasingly used in the surgical treatment of early-stage non-small cell lung cancer. However, it remains unclear whether pulmonary function loss after thoracoscopic lung resection is in direct proportion to the number of resected segments, and thus intentional thoracoscopic segmentectomy has the function-preserving advantage over thoracoscopic lobectomy.

Methods: In this prospective observational study, spirometry tests were performed preoperatively and 6 months postoperatively. The observed functional loss was compared with the expected loss estimated by the segment counting method. Resection extent index was introduced as the number of resected segments to total number of segments in the corresponding lobe. Spirometry changes after thoracoscopic lobectomy and intentional thoracoscopic segmentectomy were compared using propensity score matching.

Results: There were 338 thoracoscopic lobectomies and 321 thoracoscopic segmentectomies. Overall, the observed pulmonary function loss after segmentectomy was significantly less than after lobectomy. But the observed functional loss was significantly greater than the expected loss after segmentectomy. And pulmonary function loss per segment resected was almost doubled after segmentectomy comparing to lobectomy. For segmentectomies with a resection extent index less than 0.5 , especially single segmentectomies, pulmonary function loss was significantly less than after corresponding lobectomies. Otherwise, no significant differences in spirometry changes between lobectomies and segmentectomies were detected.

Conclusions: Pulmonary function loss after thoracoscopic lung resection cannot be accurately evaluated by the number of resected segments. According to the resection extent index, intentional thoracoscopic segmentectomy may help preserve more pulmonary function than thoracoscopic lobectomy only when less than half of the corresponding lobe are resected.

Keywords: Lobectomy; pulmonary function; segmentectomy; video-assisted thoracic surgery (VATS)

Submitted Aug 20, 2021. Accepted for publication Oct 22, 2021.

doi: $10.21037 /$ tlcr-21-661

View this article at: https://dx.doi.org/10.21037/tlcr-21-661 


\section{Introduction}

Lung cancer remains one of the leading causes of cancer incidence and mortality worldwide (1). Over the past decades, lobectomy with systemic lymph node dissection has been the gold standard for surgical treatment of stage IA non-small cell lung cancer (NSCLC). With the increasing use of low-dose computed tomographic screening, lung cancers tend to be diagnosed at an earlier stage (2). Sublobar resection such as segmentectomy, which used to be applied only in functionally compromised patients (3), is now increasingly used as an intentional procedure in goodrisk surgical candidates. The two phase III multicenter prospective randomized trials comparing lobectomy and sublobar resections (JCOG0802/WJOG4607L and CALGB/ALLIANCE 140503) have already reported their perioperative outcomes $(4,5)$, showing little difference between lobectomy and segmentectomy in the perioperative mortality and morbidity in functionally fit patients. Recently, JCOG0802/WJOG4607L trial has reported its follow-up results, revealing that segmentectomy might offer survival and functional benefits over lobectomy (6).

One of the major reasons for performing segmentectomy instead of lobectomy in good-risk patients is that segmentectomy may help preserve more pulmonary function than lobectomy, which is based on the assumption that postoperative pulmonary function loss is in direct proportion to the number of lung parenchyma units resected (7). In this study, we aimed to verify the consistency between expected and postoperative function loss actually observed after video-assisted thoracic surgery (VATS) in good-risk patients, taking into account that postoperative pulmonary function changes may be affected by the various factors including baseline lung function, the interval between surgery and the postoperative spirometry test, surgical incisions, different compensatory lung expansion after various extent of resections and location of the resected lobes (8). In addition, we further investigated which VATS segmental resections would be truly superior to its corresponding VATS lobectomy in pulmonary function preservation, as according to our previous findings, VATS segmentectomy was associated with better pulmonary function preservation in general, but was also associated with more function loss per segment resected than VATS lobectomy (9). We present the following article in accordance with the STROBE reporting checklist (available at https://dx.doi.org/10.21037/tlcr-21-661).

\section{Methods}

\section{Study design}

This was a prospective observational study in consecutive patients who underwent thoracoscopic lobectomy or segmentectomy for clinical stage IA NSCLC according to the eighth edition TNM stage classification (10) by a single team of surgeons at the Shanghai Chest Hospital during 2012 to 2018. The study was conducted in accordance with the Declaration of Helsinki (as revised in 2013). The study was approved by the ethical committee of the Shanghai Chest Hospital (No. ks11014) and informed consent was taken from all individual participants. All patients included in this study were functionally fit for standard lobectomy. Exclusion criteria were as follows (Figure 1): patients with a history of previous lung surgery on the ipsilateral side, lesions in the right middle lobe or need multiple resections in different lobes. Patients in whom postoperative adjuvant therapies were considered necessary were also excluded for fear that follow-up treatment might have certain impact on pulmonary function recovery (11). Patients who suffered severe postoperative complications were not included, such as bronchopleural fistula, respiratory failure, pulmonary embolism, etc. And those who had inadvertent phrenic nerve injury during surgery were also not included (12). The indications for intentional segmentectomy in the current study followed the National Comprehensive Cancer Network guideline, which were peripherally located nodules $\leq 2 \mathrm{~cm}$ whereby a safe resection margin could be achieved by sublobar resection, together with at least one of the following factors: pure adenocarcinoma in situ, nodules with $\geq 50 \%$ ground-glass appearance on computed tomography, radiologic surveillance confirmed a long doubling time ( $\geq 400$ days) (13). Otherwise, a lobectomy was considered necessary. Both procedures were conducted by three-port VATS. Segmental pulmonary veins, arteries, and bronchus were divided separately during segmentectomy. Staplers were used to divide the intersegmental plane according to an inflation-deflation line (14). Single segmentectomy was defined as resection of only one segment, while combined segmentectomy referred to resection of two or more adjacent segments.

\section{Postoperative course and follow-up}

After the surgery, all the patients were encouraged to become ambulatory and do the respiratory function 


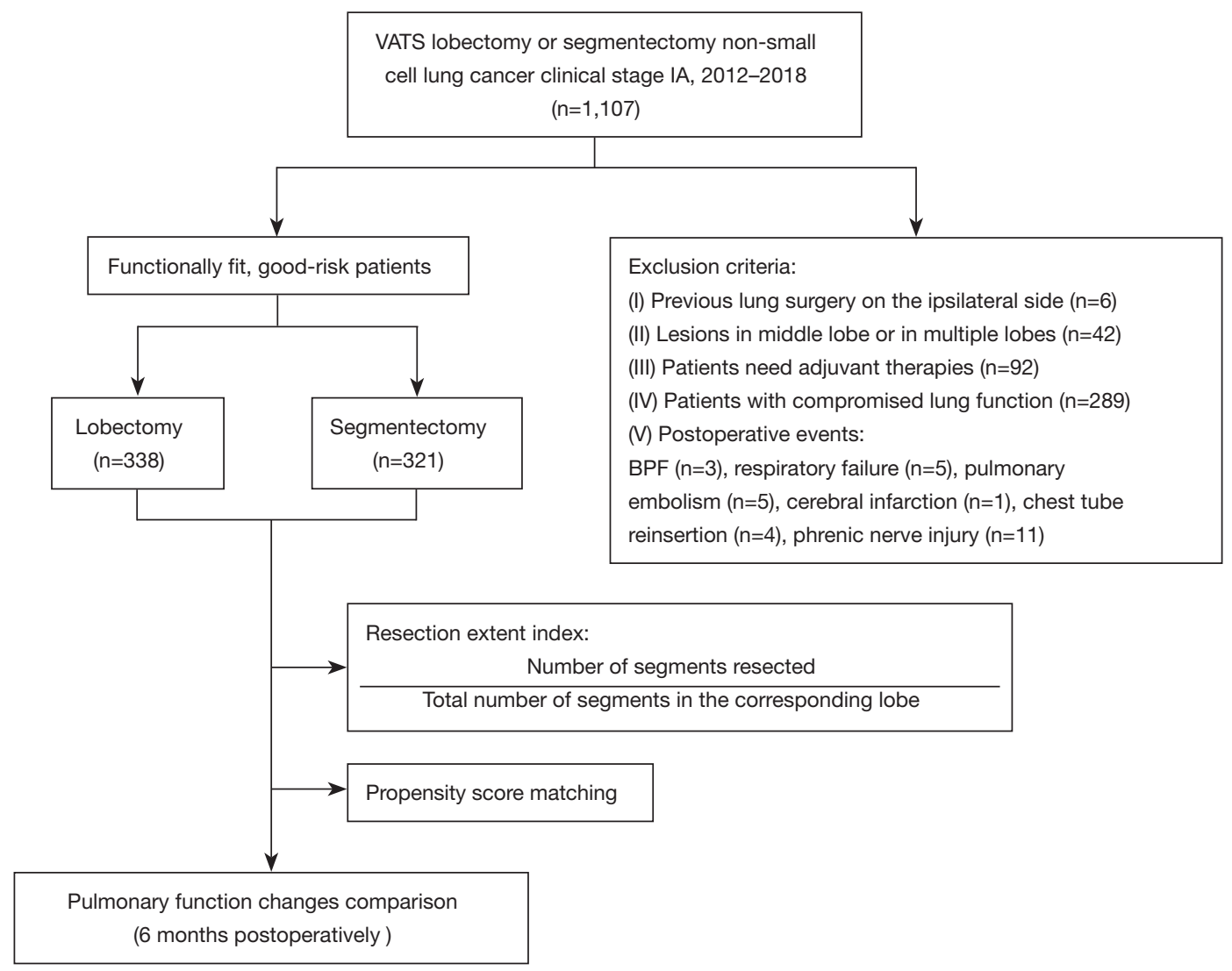

Figure 1 The flow chart of the patients in this study. BPF, bronchopleural fistula; VATS, video-assisted thoracic surgery.

training, and they were discharged with good lung expansion. No reoperation or readmission occurred in patients included in this study. And the postoperative surveillance included check up of recovery and evaluation of potential adjuvant therapies one month after surgery, chest CT scan, serum tumor markers, neck and abdominal ultrasonography performed every 6 months during the first 2 years and then annually.

\section{Pulmonary function tests}

Pulmonary function tests were performed according to American Thoracic Society standards (15) preoperatively and repeated 6 months postoperatively upon follow-up at out-patient clinic, including 3 parameters: forced vital capacity (FVC), forced expiratory volume in 1 second (FEV1), and diffusing capacity of the lungs for carbon monoxide (DLCO). The expected postoperative pulmonary function was calculated based on the conventional segment counting method:

$$
\begin{aligned}
& \text { Preoperative pulmonary function } \times \\
& \left(1-\frac{\text { Number of resected segments }}{\text { Total number of segments }}\right)
\end{aligned}
$$

The total number of segments was deemed to be 18 in both lungs, including 3 in the right upper lobe, 2 in the right middle lobe, 5 in the right lower lobe, and 4 in the left upper and lower lobes each (16). The following formulas were used to evaluate the observed or expected pulmonary function loss after surgery and average pulmonary function loss per segment resected, respectively:

$$
\begin{aligned}
& \text { Pulmonary function loss } \\
& =\frac{\text { Postoperative function - preoperative function }}{\text { Preoperative function }} \times 100 \%
\end{aligned}
$$

$$
\begin{aligned}
& \text { Pulmonary function loss per segment resected } \\
& =\frac{\text { Pulmonary function loss }}{\text { Number of resected segments }}
\end{aligned}
$$


The ratio of the observed to expected postoperative pulmonary function loss $(\mathrm{O} / \mathrm{E}$ ratio) was then calculated by the following formula:

$$
\text { O/E ratio }=\frac{\text { The observed pulmonary function loss }}{\text { The expected pulmonary function loss }}
$$

Resection extent index (listed in Table S1) was calculated as follows:

$$
\frac{\text { Number of resected segments }}{\text { Total number of segments in the corresponding lobe }}
$$

Since average functional loss per segment resected was found to be almost doubled after segmentectomies than after lobectomies in our previous study (9), indicating that when the number of resected segments was reaching half of the corresponding lobe, the potential functional benefit of segmentectomy would become negligible. Thus, the cutoff point for resection extent index in this study was set at 0.5 .

\section{Statistical analysis}

Categorical variables were expressed as count and percentage, while continuous variables were presented as mean \pm standard deviation. Differences in categorical variables were assessed by Chi-squared test, while Student's $t$-test was used to compare continuous variables. The consistency between observed and expected pulmonary function loss was evaluated by intraclass correlation coefficients (ICC) for single measures with a two-way random model and absolute agreement, and the ICC value greater than 0.70 was considered acceptable (17). Since this was not a randomized trial, 1:1 propensity score matching (PSM) was adopted via the nearest neighbor method, no replacement and 0.05 caliper width between the imbalanced groups to diminish the potential influences on pulmonary function preservation from the following variables: sex, age, smoking history, chronic obstructive pulmonary disease (COPD) and tumor location (lobe of resection). The indications for surgery such as tumor size or radiological features, which were not associated with outcomes due to the hypothesis in this study, were not included into the PSM model (18). Statistical significance was defined as $\mathrm{P}$ value $<0.05$. Standardized mean difference was used to evaluate the degree of baseline variable balance, representing a high degree of balance when the difference was no more than 0.1 (19). SPSS v22.0 and R Project v4.0.3 were used for analysis. GraphPad Prism v8.0 and Photoshop v2020 were used for graphics production.

\section{Results}

Altogether 659 patients were enrolled, including 338 patients with VATS lobectomy and 321 patients with VATS segmentectomy. In the VATS segmentectomy group, there were 200 single segmentectomies and 121 combined segmentectomies, including 120 cases of twosegment resection and one case of four-segment resection (Table S1). No significant difference existed in demographic characteristics between the two groups, including smoking history $(\mathrm{P}=0.683)$ and $\operatorname{COPD}(\mathrm{P}=0.779)$. No significant difference was detected in the baseline pulmonary function between the two groups (FVC: $\mathrm{P}=0.079$; FEV1: $\mathrm{P}=0.128$; DLCO: $\mathrm{P}=0.533)$. More segments were resected in the lobectomy group than in the segmentectomy group $(\mathrm{P}<0.001)$. Tumors in the segmentectomy group were of smaller sizes $(\mathrm{P}<0.001)$, in earlier $\mathrm{T}$ stages $(\mathrm{P}<0.001)$, and were of lower grade histology $(\mathrm{P}<0.001)$ than those in the lobectomy group (Table 1).

Poor consistency between the observed and expected pulmonary function loss was identified by the very low ICC values in Table 2 (none of them greater or even close to the acceptable value of 0.70 ). The observed functional loss was significantly less than the expected loss after VATS lobectomy (FVC: $\mathrm{P}<0.001$; FEV1: $\mathrm{P}=0.003$; DLCO: $\mathrm{P}<0.001)$, but greater than the expected loss after VATS segmentectomy (FVC: $\mathrm{P}<0.001$; FEV1: $\mathrm{P}<0.001$; DLCO: $\mathrm{P}=0.001)$. The $\mathrm{O} / \mathrm{E}$ ratio decreased accordingly as the number of resected segments increased (Figure 2 and Table S2).

Overall, the observed pulmonary function loss after segmentectomy was significantly less than after lobectomy (FVC: $\mathrm{P}<0.001$; FEV1: $\mathrm{P}<0.001$; DLCO: $\mathrm{P}<0.001$ ), while average pulmonary function loss per segment resected was significantly greater after segmentectomy than after lobectomy (FVC: $\mathrm{P}<0.001$; FEV1: $\mathrm{P}<0.001$; DLCO: $\mathrm{P}<0.001$, Table 2). According to the resection extent index, 205 segmentectomies with a resection extent index less than 0.5 and 55 segmentectomies with a resection extent index no less than 0.5 , paired with lobectomies respectively, were included after PSM (Figures 3,4). The baseline characteristics between the matched groups were well balanced (Figure S1), and a high degree of overlap in the distribution of propensity scores was demonstrated in Figure S2. FVC, FEV1 and DLCO loss were significantly greater after lobectomies than after single segmentectomies (FVC: $\mathrm{P}<0.001$; FEV1: $\mathrm{P}<0.001$; DLCO: $\mathrm{P}<0.001$, Figure $4 A$ ) or after segmentectomies with a resection 
Table 1 Clinical characteristics in patients receiving VATS lobectomy and VATS segmentectomy

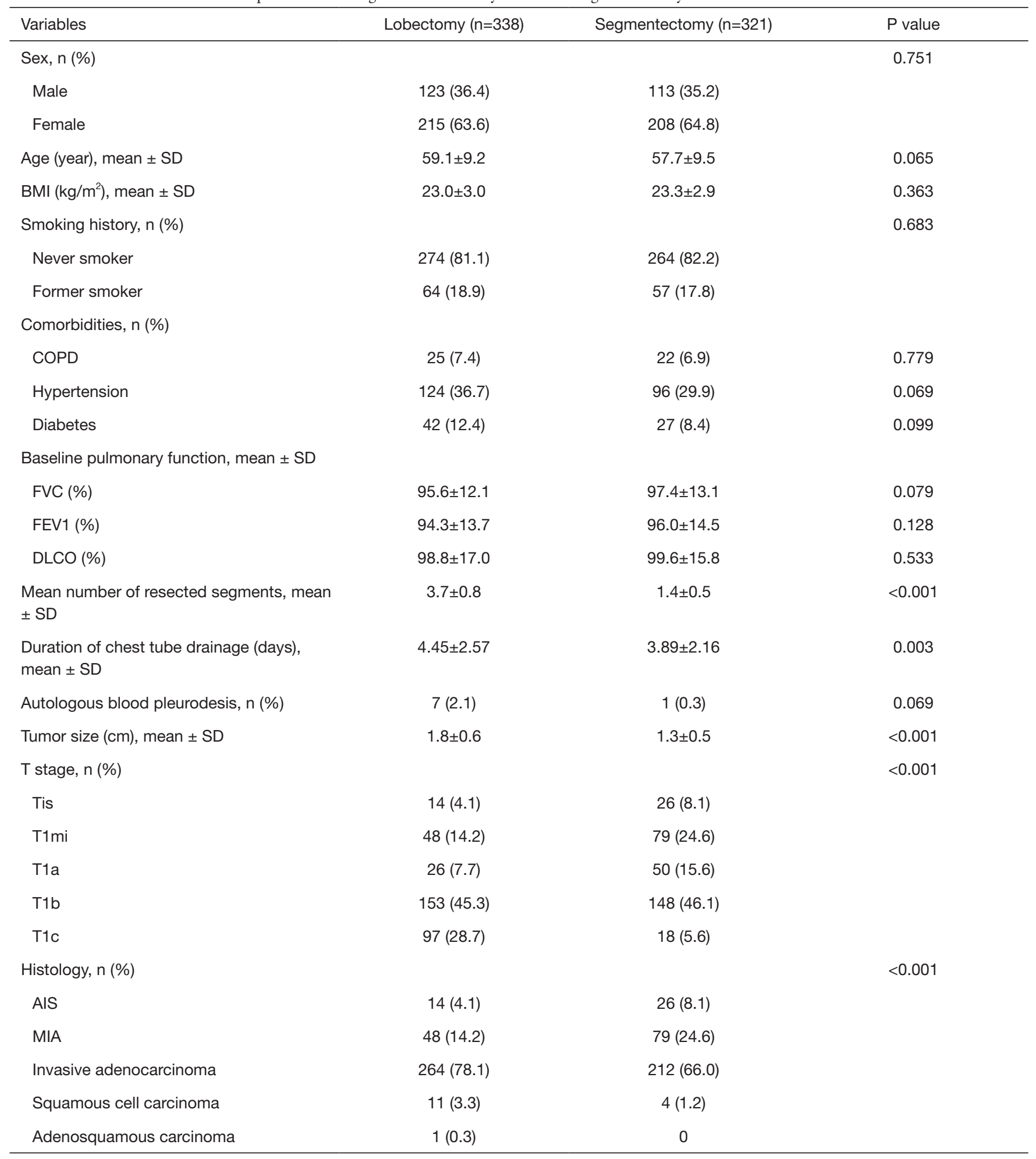

VATS, video-assisted thoracic surgery; SD, standard deviation; BMI, body mass index; COPD, chronic obstructive pulmonary disease; FVC, forced vital capacity; FEV1, forced expiratory volume in 1 second; DLCO, diffusing capacity of the lungs for carbon monoxide; AIS, adenocarcinoma in situ; MIA, minimally invasive adenocarcinoma. 
Table 2 Differences between the observed and expected postoperative pulmonary function changes in patients receiving VATS lobectomy and VATS segmentectomy

\begin{tabular}{|c|c|c|c|c|c|}
\hline Parameters & $\begin{array}{c}\text { Expected PFT } \\
\text { loss (\%) }\end{array}$ & $\begin{array}{l}\text { Observed PFT } \\
\text { loss (\%) }\end{array}$ & $\begin{array}{c}\text { Observed PFT loss per } \\
\text { segment }(\%)\end{array}$ & P value ${ }^{*}$ & ICC \\
\hline \multicolumn{6}{|c|}{ Lobectomy $(n=338)$} \\
\hline FEV1 & $-20.7 \pm 4.5$ & $-18.9 \pm 10.4^{\dagger}$ & $-5.3 \pm 3.2^{\dagger}$ & 0.003 & 0.007 \\
\hline DLCO & $-20.7 \pm 4.5$ & $-13.6 \pm 13.0^{\dagger}$ & $-3.7 \pm 3.7^{\dagger}$ & $<0.001$ & 0.087 \\
\hline FVC & $-7.7 \pm 2.8$ & $-12.1 \pm 8.6^{\dagger}$ & $-9.3 \pm 7.4^{\dagger}$ & $<0.001$ & 0.101 \\
\hline FEV1 & $-7.7 \pm 2.8$ & $-14.6 \pm 8.3^{\dagger}$ & $-11.4 \pm 7.4^{\dagger}$ & $<0.001$ & 0.075 \\
\hline DLCO & $-7.7 \pm 2.8$ & $-9.9 \pm 12.2^{\dagger}$ & $-7.8 \pm 10.9^{\dagger}$ & 0.001 & 0.050 \\
\hline
\end{tabular}

${ }^{\dagger}$, significant differences were observed in the corresponding pulmonary function parameters between VATS lobectomy and VATS segmentectomy. *, P value for the difference between observed and expected PFT loss. VATS, video-assisted thoracic surgery; PFT, pulmonary function test; ICC, intraclass correlation coefficient; FVC, forced vital capacity; FEV1, forced expiratory volume in 1 second; DLCO, diffusing capacity of the lungs for carbon monoxide.

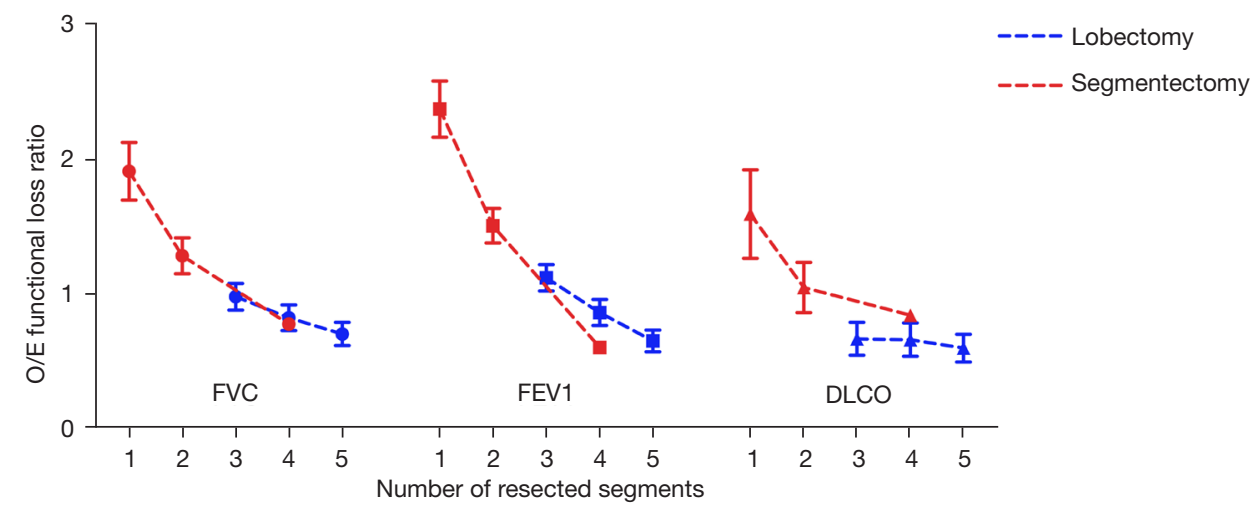

Figure 2 The ratio of the observed to the expected (O/E ratio) postoperative pulmonary function loss based on the number of resected segments. The dots represent the mean values of the ratios, while the upper and lower whiskers represent $95 \%$ confidence intervals. The dashed lines connecting each dot depict the tendency of change in the O/E ratio. DLCO, diffusing capacity of the lungs for carbon monoxide; FEV1, forced expiratory volume in 1 second; FVC, forced vital capacity.

extent index less than 0.5 (FVC: $\mathrm{P}<0.001$; FEV1: $\mathrm{P}<0.001$; DLCO: $\mathrm{P}<0.001$, Table 3 and Figure $4 B)$. When the resection extent index was equal to or greater than 0.5 , no significant difference in the functional loss was detected between segmentectomy and lobectomy (FVC: $\mathrm{P}=0.125$; FEV1: $\mathrm{P}=0.145$; DLCO: $\mathrm{P}=0.357$, Table 3 and Figure $4 C$ ) after PSM.

\section{Discussion}

Segmentectomy is now increasingly used in the surgical treatment for early-stage lung cancer. But its advantages over lobectomy remain unclear, especially as an intentional procedure for good-risk patients. The Lung Cancer Study Group trial found limited functional benefits of sublobar resection compared with lobectomy at 6 months after surgery (20). But the result was controversial due to the enrollment of wedge resection, insufficient data on pulmonary function, and the open surgical approach. The JCOG0802/WJOG4607L trial has just reported its followup results, showing a very limited functional benefit (2-3\%) of segmentectomy over lobectomy (6). 


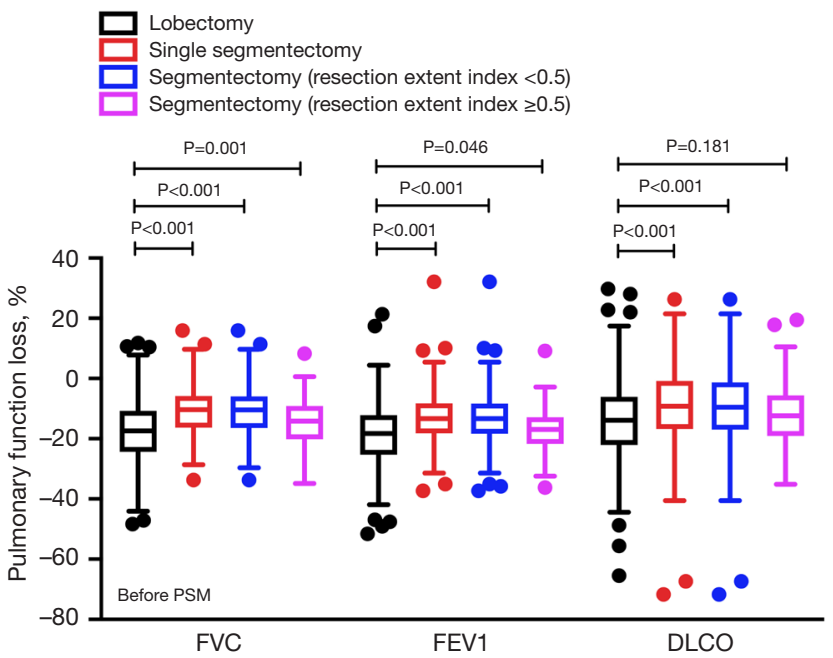

Figure 3 Comparison of pulmonary function changes between VATS lobectomy and VATS segmentectomy according to the resection extent index before propensity score matching. The upper and lower borders of the box represent the upper and lower quartiles, and the middle horizontal line represents the median, while the upper and lower whiskers represent the maximum and minimum values of non-outliers. The outliers are represented by the extra dots. DLCO, diffusing capacity of the lungs for carbon monoxide; FEV1, forced expiratory volume in 1 second; FVC, forced vital capacity; PSM, propensity score matching; VATS, video-assisted thoracic surgery.

Traditionally, pulmonary function loss after lung resection is thought to be in direct proportion to the number of resected segments, leading to the assumption that segmentectomies might preserve more function than lobectomies. However, previous studies have noticed that pulmonary function after lung resection might be inaccurately predicted by the segment counting method due to various factors including the baseline lung function, different intervals between surgery and the postoperative spirometry test $(8,21,22)$, impacts from the surgical incisions $(23,24)$, different compensatory lung expansion after various extent of resections and various lobes resected (25). In this study, we compared the expected pulmonary function loss with the actual loss observed at a fixed interval between spirometry tests after VATS lung resection in functionally fit patients. We found that all the ICC values were much less than the acceptable value of 0.70 . The observed pulmonary function loss was significantly less than the expected loss after VATS lobectomy, but was greater than the expected loss after VATS segmentectomy. This means that actual pulmonary function loss would be overestimated after VATS lobectomy, but underestimated after VATS segmentectomy, if the segment counting method was used. The gradual decline in the $\mathrm{O} / \mathrm{E}$ ratio along with the increased number of resected segments indicated that the accuracy of prediction by the segment counting method would be greatly affected by the extent of resection. Thus, it is unwise to assume that pulmonary function loss after VATS lung resection would be in direct proportion with the extent of resection.

Only a limited number of retrospective small-sample studies have compared functional changes after lobectomy and segmentectomy in the VATS setting (24-30), among which few explored pulmonary function changes after different segmentectomies $(25,29)$. Tane et al. noticed that FEV1 could be better preserved after single segmentectomy than after combined segmentectomy (25). However, due to the limited sample size, they did not compare pulmonary function changes after different segmentectomies with the corresponding lobectomies. Kuroda et al. detected significant differences in FEV1 preservation after VATS left upper lobe resections between 4 and 5-7 resected subsegments, and between 5-7 and 10 resected subsegments (29). But their study did not embark on resections of other lobes. In our prospective observational study, a much larger number of patients were included. All patients were functionally fit for lobectomy, and those receiving VATS segmentectomy were operated on with an intention-to-treat. Moreover, FVC, FEV1 and DLCO loss were all examined. Our results showed that pulmonary function loss after VATS segmentectomy was significantly less than after VATS lobectomy in general. But in consistency with the results of our previous study (9), average pulmonary function loss per segment resected after VATS segmentectomy was almost doubled than after VATS lobectomy. These results mean that less lung parenchyma resected under VATS would not necessarily translate into better function preservation, which might be potentially caused by less satisfactory re-expansion of the residual lobe after segmentectomy (9). Another reason might be that the remaining lobe(s) in the ipsilateral or contralateral lung after lobectomy expanded and compensated better than after segmentectomy, as suggested by Kim et al. (26).

To explore which VATS segmentectomies might be functionally beneficial than its corresponding VATS lobectomies, resection extent index was introduced to evaluate the loss of parenchyma and pulmonary function after surgery. And considering the impact on pulmonary function changes from different lobes resected $(26,31)$, tumor location was also included into the PSM model so 


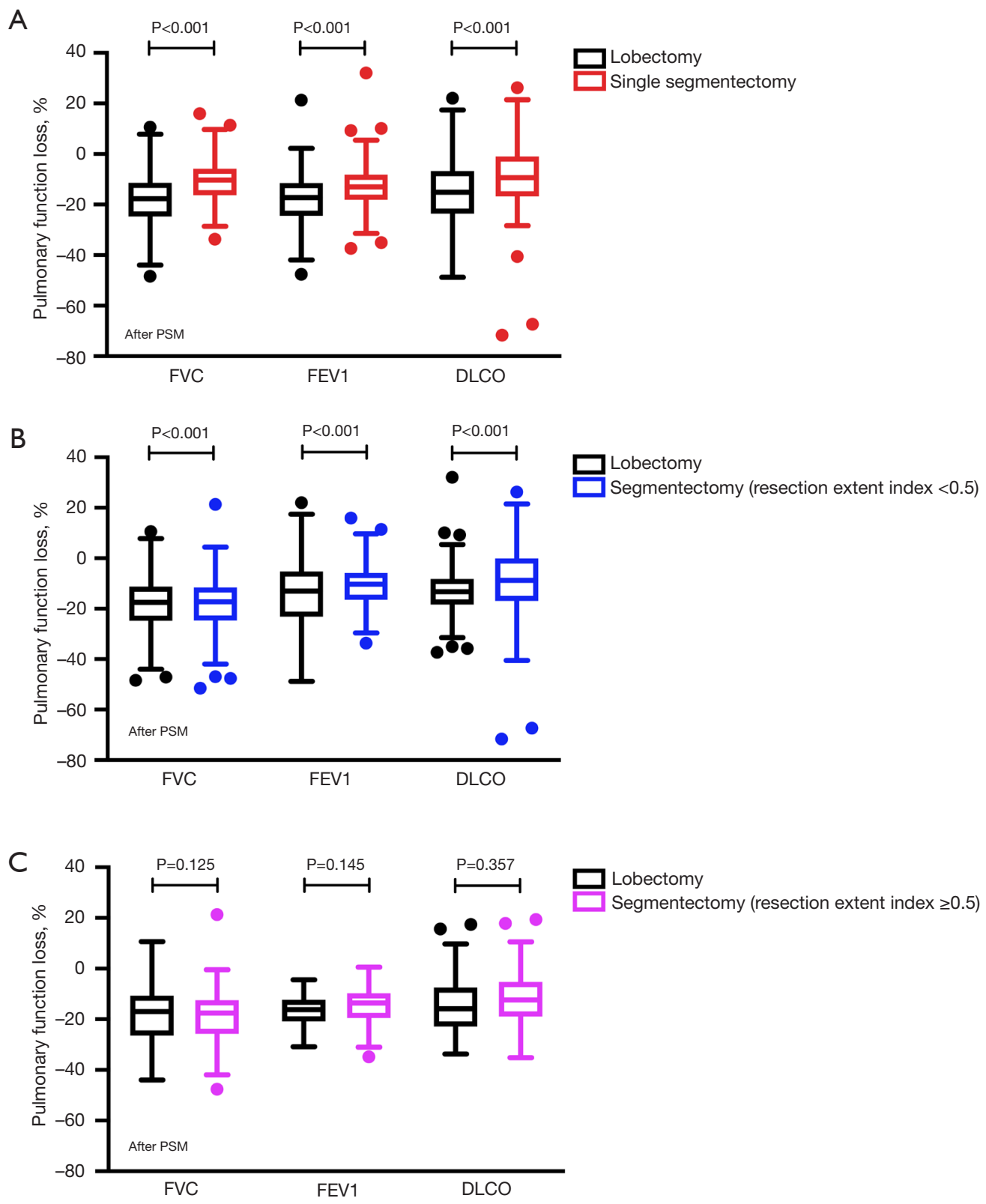

Figure 4 Comparison of pulmonary function changes after propensity score matching between lobectomy and single segmentectomy (A), segmentectomy with a resection extent index $<0.5$ (B), segmentectomy with a resection extent index $\geq 0.5$ (C). The upper and lower borders of the box represent the upper and lower quartiles, and the middle horizontal line represents the median, while the upper and lower whiskers represent the maximum and minimum values of non-outliers. The outliers are represented by the extra dots. DLCO, diffusing capacity of the lungs for carbon monoxide; FEV1, forced expiratory volume in 1 second; FVC, forced vital capacity; PSM, propensity score matching.

that functional changes after segmentectomies would be compared directly to their corresponding lobectomies, together with the other characteristics including sex, age, smoking history and COPD. We found that for segmentectomies with a resection extent index less than 0.5 , especially single segmentectomies, FVC, FEV1 and DLCO loss were all significantly less than after corresponding lobectomies. Otherwise, no significant functional advantage could be detected after segmentectomies with a resection extent index equal to or greater than 0.5 . To our knowledge, 
Table 3 Pulmonary function changes after VATS lobectomy and VATS segmentectomy evaluated according to the resection extent index before and after propensity score matching

\begin{tabular}{|c|c|c|c|c|c|c|}
\hline Parameters & \multicolumn{3}{|c|}{ Before PSM } & \multicolumn{3}{|c|}{ After PSM } \\
\hline Resection extent index $<0.5$ & $n=338$ & $n=214$ & & $n=205$ & $n=205$ & \\
\hline FVC loss (\%) & $-17.8 \pm 10.6$ & $-10.8 \pm 8.5$ & $<0.001$ & $-18.5 \pm 10.7$ & $-10.7 \pm 8.6$ & $<0.001$ \\
\hline FEV1 loss (\%) & $-18.9 \pm 10.4$ & $-13.3 \pm 8.4$ & $<0.001$ & $-18.1 \pm 10.6$ & $-13.2 \pm 8.5$ & $<0.001$ \\
\hline Resection extent index $\geq 0.5$ & $n=338$ & $n=107$ & & $n=55$ & $\mathrm{n}=55$ & \\
\hline FVC loss (\%) & $-17.8 \pm 10.6$ & $-14.6 \pm 8.1$ & 0.001 & $-17.7 \pm 12.3$ & $-14.7 \pm 7.7$ & 0.125 \\
\hline FEV1 loss (\%) & $-18.9 \pm 10.4$ & $-17.0 \pm 7.5$ & 0.046 & $-18.8 \pm 12.3$ & $-16.0 \pm 6.4$ & 0.145 \\
\hline DLCO loss (\%) & $-13.6 \pm 13.0$ & $-11.8 \pm 10.5$ & 0.181 & $-13.7 \pm 12.3$ & $-11.5 \pm 11.1$ & 0.357 \\
\hline
\end{tabular}

VATS, video-assisted thoracic surgery; PSM, propensity score matching; FVC, forced vital capacity; FEV1, forced expiratory volume in 1 second; DLCO, diffusing capacity of the lungs for carbon monoxide.

this is the first prospective observational study comparing pulmonary function changes according to different resection extent indexes after VATS lobectomy and its corresponding VATS segmentectomy solely in good-risk patients. This makes our results more convincing and helpful in predicting potential functional benefits when considering segmentectomy for early-stage lung cancers.

The present study has several limitations. This was not a randomized trial. There might have been imbalances among patients included, even with stringent efforts to diminish their impacts by PSM. The purpose for this study was to evaluate the functional benefits of segmentectomy as an intentional procedure for good-risk patients. Patients who had poor lung function were excluded during the study design. Therefore, quantitative ventilation-perfusion scans would be not essential in this study (32-34), and the results could not be extrapolated to patients with poor lung function. Then segmental planes were divided by staplers in our patients. Thus, the results may not be extrapolated to segmentectomies using energy devices to divide segmental planes (35). Meanwhile, whether the pulmonary function changes are affected by the postoperative complications such as prolonged air leakage, which is treated with autologous blood pleurodesis in the current study remains unclear $(36,37)$. Long-term pulmonary function changes may not be absolutely consistent with the results on functional changes evaluated at 6 months after surgery in this study, although longterm pulmonary function changes seem to vary little
6 months or later after surgery, as reported previously (38).

\section{Conclusions}

Pulmonary function loss after thoracoscopic lung resection is not in direct proportion to the number of resected segments. VATS segmentectomy may help preserve more pulmonary function than VATS lobectomy in general. However, average pulmonary function loss per segment resected is greater after segmentectomy than after lobectomy. Which thoracoscopic segmentectomies would be truly beneficial in pulmonary function preservation can be estimated by the resection extent index. Only for segmentectomies with a resection extent index less than 0.5 , especially single segmentectomies, more postoperative pulmonary function is preserved than the corresponding lobectomies.

\section{Acknowledgments}

Funding: This work was supported by Scientific Research Projects of Shanghai Municipal Science and Technology Commission (No. 14411950800).

\section{Footnote}

Reporting Checklist: The authors have completed the STROBE reporting checklist. Available at https://dx.doi. org/10.21037/tlcr-21-661 
Data Sharing Statement: Available at https://dx.doi. org/10.21037/tlcr-21-661

Peer Review File: Available at https://dx.doi.org/10.21037/ tlcr-21-661

Conflicts of Interest: All authors have completed the ICMJE uniform disclosure form (available at https://dx.doi. org/10.21037/tlcr-21-661). The authors have no conflicts of interest to declare.

Ethical Statement: The authors are accountable for all aspects of the work in ensuring that questions related to the accuracy or integrity of any part of the work are appropriately investigated and resolved. The study was conducted in accordance with the Declaration of Helsinki (as revised in 2013). The study was approved by the ethical committee of the Shanghai Chest Hospital (No. ks11014) and informed consent was taken from all individual participants.

Open Access Statement: This is an Open Access article distributed in accordance with the Creative Commons Attribution-NonCommercial-NoDerivs 4.0 International License (CC BY-NC-ND 4.0), which permits the noncommercial replication and distribution of the article with the strict proviso that no changes or edits are made and the original work is properly cited (including links to both the formal publication through the relevant DOI and the license). See: https://creativecommons.org/licenses/by-nc-nd/4.0/.

\section{References}

1. Bray F, Ferlay J, Soerjomataram I, et al. Global cancer statistics 2018: GLOBOCAN estimates of incidence and mortality worldwide for 36 cancers in 185 countries. CA Cancer J Clin 2018;68:394-424.

2. National Lung Screening Trial Research Team; Aberle DR, Adams AM, et al. Reduced lung-cancer mortality with low-dose computed tomographic screening. N Engl J Med 2011;365:395-409.

3. Novello S, Asamura H, Bazan J, et al. Early stage lung cancer: progress in the last 40 years corrected. J Thorac Oncol 2014;9:1434-42.

4. Suzuki K, Saji H, Aokage K, et al. Comparison of pulmonary segmentectomy and lobectomy: Safety results of a randomized trial. J Thorac Cardiovasc Surg 2019;158:895-907.
5. Altorki NK, Wang X, Wigle D, et al. Perioperative mortality and morbidity after sublobar versus lobar resection for early-stage non-small-cell lung cancer: post-hoc analysis of an international, randomised, phase 3 trial (CALGB/Alliance 140503). Lancet Respir Med 2018;6:915-24.

6. Asamura H, Okada M, Saji H, et al. Randomized trial of segmentectomy compared to lobectomy in smallsized peripheral non-small cell lung cancer. 101st Annual Meeting of American Association for Thoracic Surgery 2021:311-2.

7. Ontiveros N, Eapen-John D, Osorio N, et al. Predicting Lung Function Following Lobectomy: A New Method to Adjust for Inherent Selection Bias. Respiration 2018;96:434-45.

8. Charloux A, Quoix E. Lung segmentectomy: does it offer a real functional benefit over lobectomy? Eur Respir Rev 2017;26:170079.

9. Gu Z, Wang H, Mao T, et al. Pulmonary function changes after different extent of pulmonary resection under videoassisted thoracic surgery. J Thorac Dis 2018;10:2331-7.

10. Goldstraw P, Chansky K, Crowley J, et al. The IASLC Lung Cancer Staging Project: Proposals for Revision of the TNM Stage Groupings in the Forthcoming (Eighth) Edition of the TNM Classification for Lung Cancer. J Thorac Oncol 2016;11:39-51.

11. Nomori H, Shiraishi A, Cong Y, et al. Impact of induction chemoradiotherapy on pulmonary function after lobectomy for lung cancer. J Thorac Cardiovasc Surg 2018;155:2129-2137.e1.

12. Ventura L, Zhao W, Chen T, et al. Significant diaphragm elevation suggestive of phrenic nerve injury after thoracoscopic lobectomy for lung cancer: an underestimated problem. Transl Lung Cancer Res 2020;9:1822-31.

13. Ettinger DS, Wood DE, Aisner DL, et al. Non-Small Cell Lung Cancer, Version 5.2017, NCCN Clinical Practice Guidelines in Oncology. J Natl Compr Canc Netw 2017;15:504-35.

14. Zhong C, Fang W, Mao T, et al. Comparison of thoracoscopic segmentectomy and thoracoscopic lobectomy for small-sized stage IA lung cancer. Ann Thorac Surg 2012;94:362-7.

15. Standardization of Spirometry, 1994 Update. American Thoracic Society. Am J Respir Crit Care Med 1995; 152:1107-36.

16. Mehran RJ. Fundamental and Practical Aspects of Airway Anatomy: From Glottis to Segmental Bronchus. Thorac 
Surg Clin 2018;28:117-25.

17. Anvari A, Halpern EF, Samir AE. Statistics 101 for Radiologists. Radiographics 2015;35:1789-801.

18. Ali MS, Groenwold RH, Belitser SV, et al. Reporting of covariate selection and balance assessment in propensity score analysis is suboptimal: a systematic review. J Clin Epidemiol 2015;68:112-21.

19. McMurry TL, Hu Y, Blackstone EH, et al. Propensity scores: Methods, considerations, and applications in the Journal of Thoracic and Cardiovascular Surgery. J Thorac Cardiovasc Surg 2015;150:14-9.

20. Ginsberg RJ, Rubinstein LV. Randomized trial of lobectomy versus limited resection for T1 N0 non-small cell lung cancer. Lung Cancer Study Group. Ann Thorac Surg 1995;60:615-22; discussion 622-3.

21. Nomori H, Shiraishi A, Cong Y, et al. Differences in postoperative changes in pulmonary functions following segmentectomy compared with lobectomy. Eur J Cardiothorac Surg 2018;53:640-7.

22. Fernández-Rodríguez L, Torres I, Romera D, et al. Prediction of postoperative lung function after major lung resection for lung cancer using volumetric computed tomography. J Thorac Cardiovasc Surg 2018;156:22972308.e5.

23. Yoshiyasu N, Kojima F, Takahashi O, et al. The impact of surgical chest wall damage caused by classic thoracotomy on pulmonary function and morphology. Gen Thorac Cardiovasc Surg 2020;68:508-15.

24. Sugita Y, Kuroda H, Sakata S, et al. How preserved regional pulmonary function after thoracoscopic segmentectomy in clinical stage I non-small cell lung cancers in right upper lobe. Gen Thorac Cardiovasc Surg 2021;69:960-6.

25. Tane $S$, Nishio W, Nishioka $Y$, et al. Evaluation of the Residual Lung Function After Thoracoscopic Segmentectomy Compared With Lobectomy. Ann Thorac Surg 2019;108:1543-50.

26. Kim SJ, Lee YJ, Park JS, et al. Changes in pulmonary function in lung cancer patients after video-assisted thoracic surgery. Ann Thorac Surg 2015;99:210-7.

27. Echavarria MF, Cheng AM, Velez-Cubian FO, et al. Comparison of pulmonary function tests and perioperative outcomes after robotic-assisted pulmonary lobectomy vs segmentectomy. Am J Surg 2016;212:1175-82.

28. Hwang Y, Kang CH, Kim HS, et al. Comparison of thoracoscopic segmentectomy and thoracoscopic lobectomy on the patients with non-small cell lung cancer: a propensity score matching study. Eur J Cardiothorac
Surg 2015;48:273-8.

29. Kuroda H, Sakata S, Takahashi Y, et al. Subsegmental resection preserves regional pulmonary function: A focus on thoracoscopy. Thorac Cancer 2021;12:1033-40.

30. Tane S, Nishio W, Fujibayashi $Y$, et al. Thoracoscopic left $\mathrm{S} 1+2$ segmentectomy as a good resolution for preserving pulmonary function. Interact Cardiovasc Thorac Surg 2020;31:331-8.

31. Kim SJ, Ahn S, Lee YJ, et al. Factors associated with preserved pulmonary function in non-small-cell lung cancer patients after video-assisted thoracic surgery. Eur J Cardiothorac Surg 2016;49:1084-90.

32. Yokoba M, Ichikawa T, Harada S, et al. Comparison between quantitative computed tomography, scintigraphy, and anatomical methods for prediction of postoperative FEV1 and DLCO: effects of chronic obstructive pulmonary disease status and resected lobes. J Thorac Dis 2020;12:5269-80.

33. Win T, Laroche CM, Groves AM, et al. Use of quantitative lung scintigraphy to predict postoperative pulmonary function in lung cancer patients undergoing lobectomy. Ann Thorac Surg 2004;78:1215-8.

34. Holvoet T, van Meerbeeck JP, Van De Wiele C, et al. Quantitative Perfusion Scintigraphy or Anatomic Segment Method in lung cancer resection. Lung Cancer 2011;74:212-8.

35. Chen X, Jin R, Xiang J, et al. Methods for Dissecting Intersegmental Planes in Segmentectomy: A Randomized Controlled Trial. Ann Thorac Surg 2020;110:258-64.

36. Cobanoglu U, Melek M, Edirne Y. Autologous blood pleurodesis: A good choice in patients with persistent air leak. Ann Thorac Med 2009;4:182-6.

37. Maeyashiki T, Takamochi K, Matsunaga T, et al. Negative impact of chemical pleurodesis on postoperative pulmonary function for managing prolonged air leakage after segmentectomy. Gen Thorac Cardiovasc Surg 2021;69:707-15.

38. Kim HK, Lee YJ, Han KN, et al. Pulmonary Function Changes Over 1 Year After Lobectomy in Lung Cancer. Respir Care 2016;61:376-82.

Cite this article as: Chen $\mathrm{L}, \mathrm{Gu} \mathrm{Z}$, Lin B, Wang $\mathrm{W}, \mathrm{Xu}$ N, Liu Y, Ji C, Fang W. Pulmonary function changes after thoracoscopic lobectomy versus intentional thoracoscopic segmentectomy for early-stage non-small cell lung cancer. Transl Lung Cancer Res 2021;10(11):4141-4151. doi: 10.21037/ tlcr-21-661 
Supplementary

Table S1 Surgical procedures in patients receiving VATS lobectomy and VATS segmentectomy

\begin{tabular}{|c|c|c|c|c|c|}
\hline Variables & Lobectomy (n=338) & Segmentectomy $(n=321)$ & Segments contained & Resection extent index & $P$ value ${ }^{*}$ \\
\hline Location and procedures & & & & & $<0.001$ \\
\hline RUL & $166(49.1 \%)$ & $78(24.3 \%)$ & 3 & 1.00 & \\
\hline $\mathrm{S}_{1}$ & - & 36 & 1 & 0.33 & \\
\hline $\mathrm{S}_{2}$ & - & 30 & 1 & 0.33 & \\
\hline $\mathrm{S}_{1}+\mathrm{S}_{2}$ & - & 1 & 2 & 0.67 & \\
\hline $\mathrm{S}_{3}$ & - & 11 & 1 & 0.33 & \\
\hline RLL & 75 (22.2\%) & $50(15.6 \%)$ & 5 & 1.00 & \\
\hline $\mathrm{S}_{6}$ & - & 33 & 1 & 0.20 & \\
\hline $\mathrm{S}_{7}$ & - & 1 & 1 & 0.20 & \\
\hline $\mathrm{S}_{8}$ & - & 1 & 1 & 0.20 & \\
\hline $\mathrm{S}_{7}+\mathrm{S}_{8}$ & - & 10 & 2 & 0.40 & \\
\hline$S_{9}+S_{10}$ & - & 4 & 2 & 0.40 & \\
\hline$S_{7}+S_{8}+S_{9}+S_{10}$ & - & 1 & 4 & 0.80 & \\
\hline LUL & $48(14.2 \%)$ & 157 (48.9\%) & 4 & 1.00 & \\
\hline $\mathrm{S}_{1+2}$ & - & 42 & 1 & 0.25 & \\
\hline $\mathrm{S}_{1+2}+\mathrm{S}_{3}$ & - & 79 & 2 & 0.50 & \\
\hline $\mathrm{S}_{3}$ & - & 15 & 1 & 0.25 & \\
\hline $\mathrm{S}_{4}+\mathrm{S}_{5}$ & - & 21 & 2 & 0.50 & \\
\hline LLL & $49(14.5 \%)$ & $36(11.2 \%)$ & 4 & 1.00 & \\
\hline $\mathrm{S}_{6}$ & - & 19 & 1 & 0.25 & \\
\hline $\mathrm{S}_{8}$ & - & 12 & 1 & 0.25 & \\
\hline$S_{9}+S_{10}$ & - & 5 & 2 & 0.50 & \\
\hline
\end{tabular}

*, $\mathrm{P}$ value for the difference in tumor location between lobectomy and segmentectomy. RUL, right upper lobe; RLL, right lower lobe; LUL, left upper lobe; LLL, left lower lobe; VATS, video-assisted thoracic surgery. 


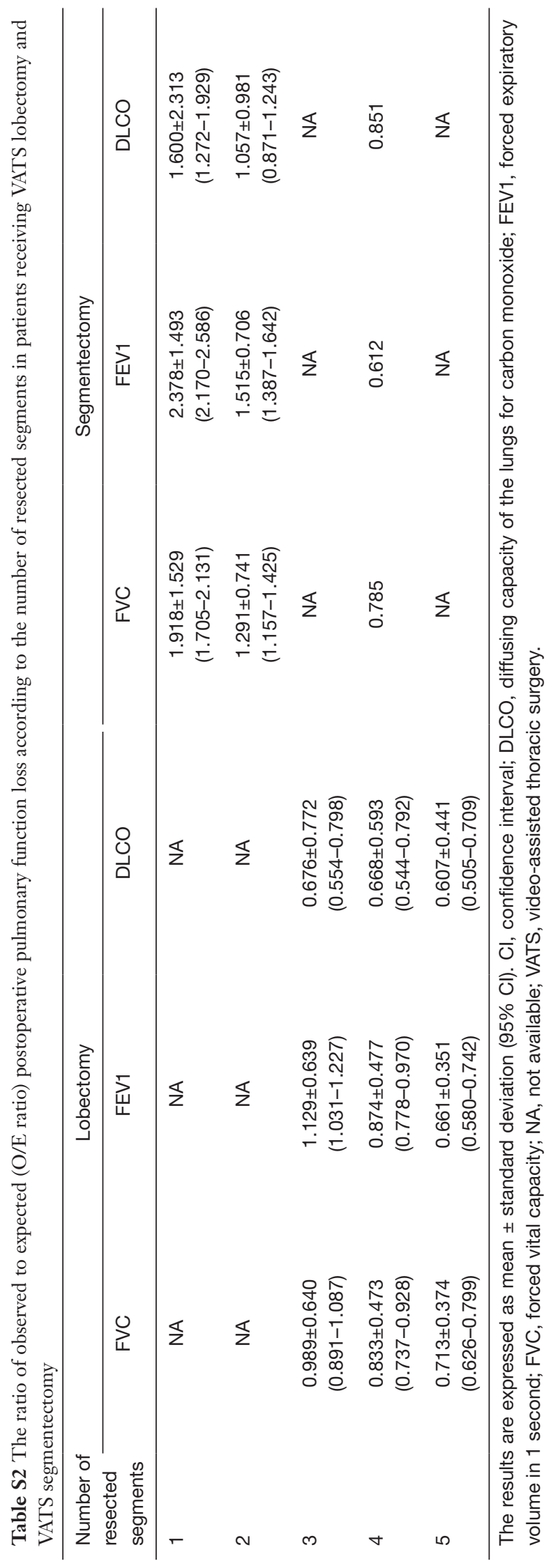

(c) Translational Lung Cancer Research. All rights reserved. 
A

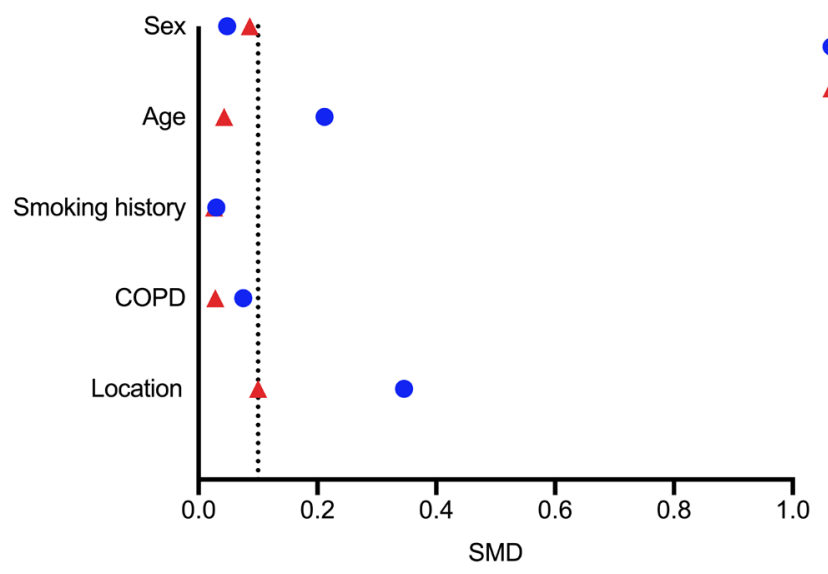

- Before PSM

- After PSM

B

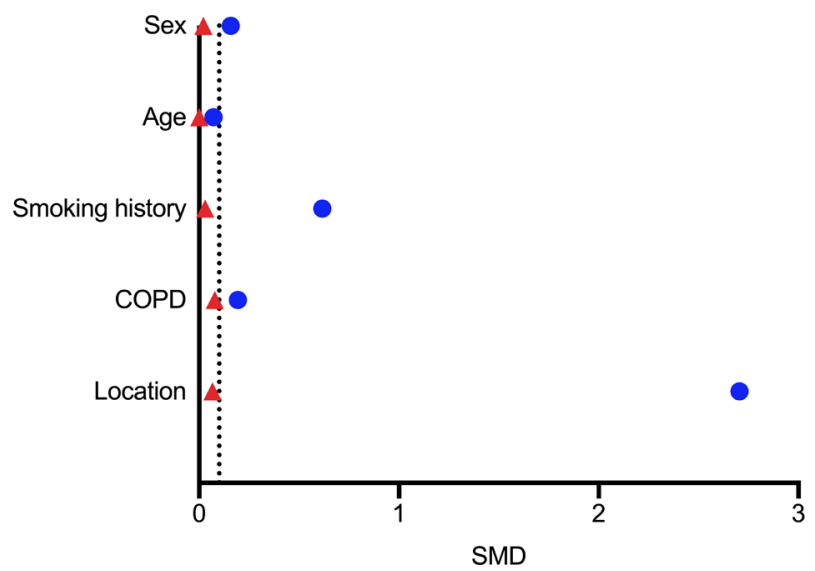

- Before PSM

- After PSM

Figure S1 Evaluation of baseline variable balance by standardized mean difference before and after propensity score matching. (A) Comparison between lobectomy and segmentectomy with a resection extent index $<0.5$. (B) Comparison between lobectomy and segmentectomy with a resection extent index $\geq 0.5$. The SMD value no more than 0.1 (within the dotted lines) represents a high degree of balance. COPD, chronic obstructive pulmonary disease; PSM, propensity score matching; SMD, standardized mean difference. 


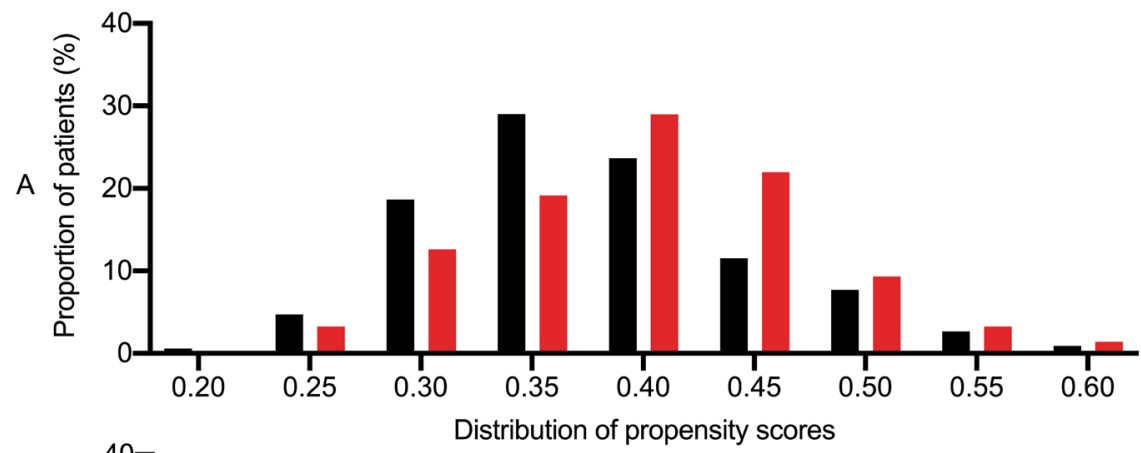

Lobectomy

Segmentectomy

(resection extent index $<0.5$ )

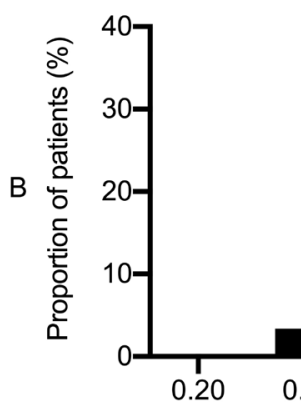

Distribution of propensity scores

Lobectomy

Segmentectomy

(resection extent index $<0.5$ )

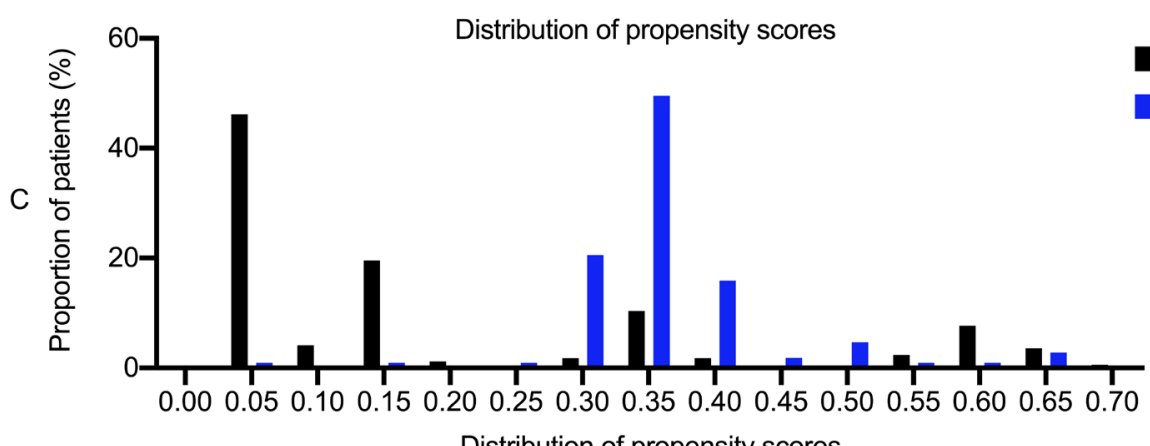

Lobectomy

Segmentectomy

(resection extent index $\geq 0.5$ )

Distribution of propensity scores

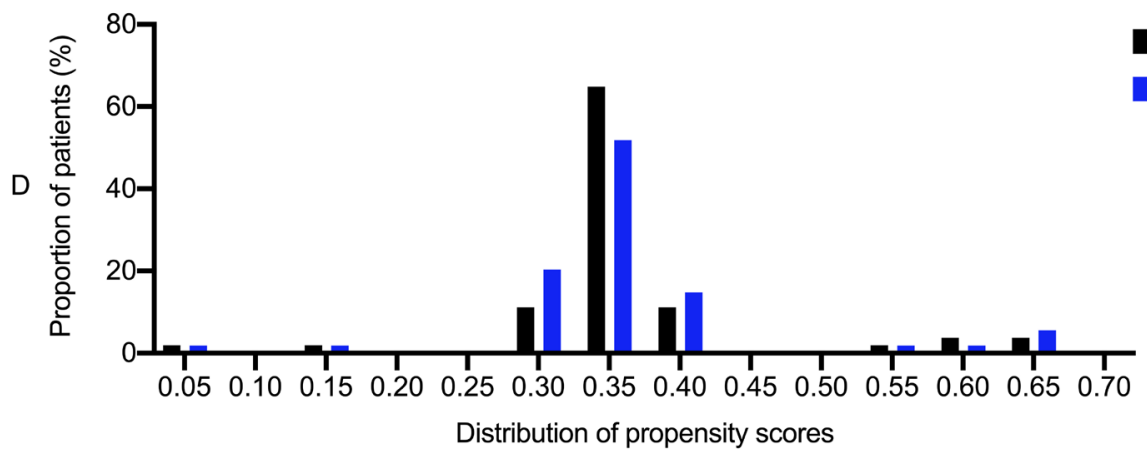

Lobectomy

Segmentectomy

(resection extent index $\geq 0.5$ )

Distribution of propensity scores

Figure S2 The distribution of propensity scores before (A,C) and after (B,D) propensity score matching. 